\title{
Wear and Corrosion Resistant Amorphous / Nanostructured Steel Coatings For Replacement Of Electrolytic Hard Chromium
}

\author{
D.J. Branagan, M.C. Marshall, \& B.E. Meacham, \\ The NanoSteel Company \\ and \\ L. F. Aprigliano, \\ Naval Surface Warfare Center \\ and \\ R. Bayles, E. J. Lemieux, T. M. Wolejsza \& F. J. Martin, \\ Naval Research Laboratory \& Geo-Centers Corporation \\ and \\ J. C. Farmer, J. J. Haslam, \& S. D. Day, \\ Lawrence Livermore National Laboratory, USDOE
}

In severe corrosive or abrasive environments, steel is rarely used since the range of properties available, in existing steels, are insufficient, resulting in the prevalent usage of either corrosion resistant materials like nickel based superalloys or abrasion resistant materials like tungsten carbide based hardmetals. Recently, a host of carbide based alloys including WC-Co-Cr, $\mathrm{NiCr}-\mathrm{Cr}_{3} \mathrm{C}_{2}, \mathrm{WC}-\mathrm{Cr}_{3} \mathrm{C}_{2}-\mathrm{Ni}$ etc. have been developed in an attempt to bridge the gap between providing both wear and corrosion protection. In this presentation, data will be presented showing how a newly developed steel coating, SAM2X5, with an amorphous / nanocomposite structure can bridge the gap between conventional metallic alloys and ceramic hardmetal performance with excellent combinations of properties including corrosion resistance superior to nickel superalloys in a number of environments and wear resistance approaching that of tungsten carbide cobalt. The unique combination of damage tolerance developed should be especially applicable for the replacement of electrolytic hard chromium. 